\title{
Oxidation of ethoxylated fatty alcohols to alkylpolyglycol carboxylic acids using noble metals as catalysts
}

\author{
By Spiros Zlatanos, ${ }^{a,{ }^{*}}$ Kostas Laskaridis ${ }^{a}$ and Angelos Sagredos ${ }^{a}$ \\ a Chemical Engineering Department, Aristotle University of Thessaloniki, \\ 54124 Thessaloniki, Greece. \\ ("corresponding author: szlatano@eng.auth.gr)
}

\section{RESUMEN}

Oxidación de alcoholes grasos etoxilados a ácidos carboxílicos alquilpoliglicólicos usando metales nobles como catalizadores.

La conversión de alcoholes grasos etoxilados a los correspondientes ácidos carboxílicos por deshidrogenación/ oxidación con metales nobles como catalizador ha sido estudiada. Alcoholes primarios alifáticos etoxilados, alcoholes alifáticos secundarios etoxilados al azar y alquilfenoles etoxilados han sido convertidos a los correspondientes ácidos en presencia de base. Los catalizadores paladio y platino fueron usados sin degradación significativa de las cadenas etoxiladas con un rendimiento que excedió del $90 \%$. Por otra parte catalizadores de rodio y rutenio produjeron rendimientos del 80 y $60 \%$, respectivamente.

PALABRAS CLAVE: Ácido carboxílico alquilpoliglicólicos - Ácido carboxílico etoxilado - Alcohol graso etoxilado Deshidrogenación catalizada por metales nobles - Oxidación catalizada por metales nobles.

\section{SUMMARY}

Oxidation of ethoxylated fatty alcohols to alkylpolyglycol carboxylic acids using noble metals as catalysts

The conversion of ethoxylated fatty alcohols to the corresponding carboxylic acids through dehydrogenation/ oxidation using noble-metal catalysts has been studied. Ethoxylated primary aliphatic alcohols, ethoxylated random secondary aliphatic alcohols and ethoxylated alkylphenols have been converted to the corresponding acids in the presence of a base. The noble metal catalysts Palladium and Platinum were used without significant degradation of the ethoxyl chain in yields that exceeded $90 \%$. On the other hand, the catalysts Rhodium and Ruthenium gave yields of about $80 \%$ and $60 \%$ respectively.

KEY-WORDS: Alkylpolyglycol carboxylic acid - Ethoxy carboxylic acid - Fatty alcohol ethoxylate - Noble-metal catalyst Oxidation - Noble-metal catalyst Dehydrogenation.

\section{INTRODUCTION}

Alkylpolyglycol carboxylic acids (3) were already prepared by the reaction of ethoxylated alcohols (1) with chloracetic acid (2) (Aalbers, 1964):

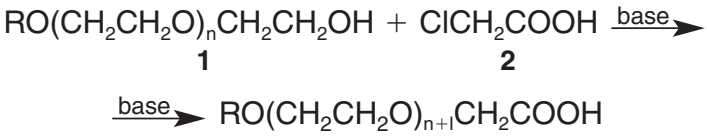

This method gives maximum conversion up to $90 \%$, but the process is less practical because chloracetic acid is a strong acid and an environmental contaminant with etching, corrosive and toxic properties. The extensive application of this method demands diligent safety measures for the workers and the environment and makes it inconvenient and expensive. In addition, the product of this reaction is not the corresponding carboxylic acid with the same carbon chain as the ethoxylated alcohol, but an acid with two additional carbons.

Oxidation with conventional oxidants (among others $\mathrm{KMnO}_{4}$ ) and autoxidation in the presence of soluble transition-metal catalysts give poor yields according to our experience.

The oxidation of primary alcohols to acids with oxygen using platinum catalyst has been reported previously in the literature (Heyns et al., 1957, Heyns et al., 1960, Heyns et al., 1962, Bekkum, 1990, Roper, 1990, Vinke et al., 1992, Haines et al., 1998). Alcohols could be converted to salts of the corresponding acids in the presence of bases $\left(\mathrm{Na}_{2} \mathrm{CO}_{3}, \mathrm{NaOH}\right)$ in yields which depend on the structure of the alcohol.

$$
\mathrm{RCH}_{2} \mathrm{OH}+\underset{4}{\mathrm{NaOH}}+\mathrm{O}_{2} \frac{\mathrm{Pt}}{70-75^{\circ} \mathrm{C} \text { in } \mathrm{H}_{2} \mathrm{O}} \underset{\mathbf{5}}{\longrightarrow} \underset{\mathrm{RCH}_{2} \mathrm{COONa}}{\mathrm{CON}}
$$

Further studies conducted by Mallat and Baiker (Mallat et al., 1994, Mallat et al., 1995) regarding the oxidation of alcohols with molecular oxygen to the respective acids using platinum catalysts have shown that the participation of a second metal (mainly $\mathrm{Bi}$ and $\mathrm{Pb}$ ) is useful as a reaction promoter. Furthermore, the effect of the $\mathrm{pH}$ on the oxidation rate has been comprehensively studied as well as its effect on the route of the reaction (Mallat et al., 1994, Gangwal et al., 2004). Finally, recent studies 
(Korovchenko et al., 2007, Sheldon et al., 2000, Zhan et al., 2004, Mallat et al., 1995) are concentrated on the conditions that increase the yield of the produced acids, or aldehydes, after oxidising primary alcohols with a platinum catalyst. In this way oxygen becomes the most useful reagent as it is not toxic and its supply is readily available and inexpensive.

The aim of this work was a convenient oxidation of ethoxylated primary and secondary aliphatic alcohols $(1, R=$ alkyl)

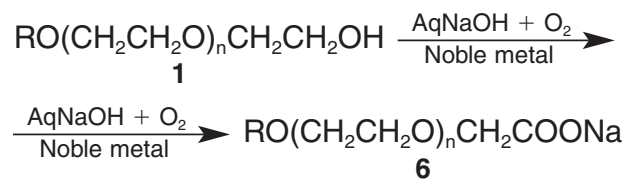

as well as of ethoxylated alkylphenols $(7, \mathrm{R}=$ alkyl)

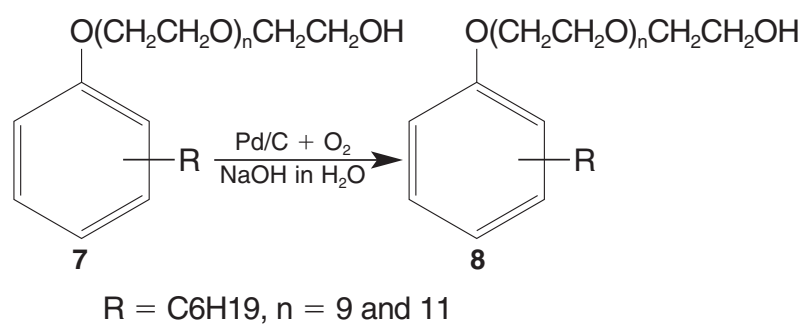

to the corresponding alkylpolyglycol carboxylic acids using platinum and other noble catalysts with oxygen in an aqueous alkaline solution (6 and 8).

This noble-metal catalysed oxidation was considered to be of great interest for the synthesis of alkylpolyglycol carboxylic acids as it gives high yields without degradation or elongation of the ethoxyl chain and avoids environmental problems. In addition, this reaction is achieved with relatively low costs because of the small amount of catalysts it requires and the possibility of regenerating them.

\section{MATERIALS AND METHODS}

\subsection{Catalysts and Reagents}

In the present study the noble metals Platinum (as $\mathrm{PtO}_{2}$, reduced in situ for $6 \mathrm{hr}$ with hydrogen to Pt, Merck), Palladium (10\% on charcoal, Merck), Rhodium (5\% on charcoal, Merck), Ruthenium (10\% on charcoal, Merck) were used as catalysts according to Schiller (1955).

Three types of fatty alcohols were employed, selected as representing different ethoxy-(EO) chain lengths and two different modes of attachment of ethoxy chain to hydrophobe chain.

\section{Ethoxylated n-primary alcohols}

A mixture was made of approximately $60 \% 1$ dodecanol (compound 1, with $\mathrm{R}=\mathrm{C}_{12} \mathrm{H}_{25}$ and $\mathrm{n}=$ 2) and 40\% 1-tetradecanol (1, with $\mathrm{R}=\mathrm{C}_{14} \mathrm{H}_{29}$ and $\mathrm{n}=2$ ) ethoxylated with $3 \mathrm{EO}$ units (Union Carbide). The following analytical data were determined for the IR-spectrum: Strong broad $\mathrm{OH}$ absorption at $3470 \mathrm{~cm}^{-1}$, strong broad C-H absorption at $2960-$ $2840 \mathrm{~cm}^{-1}$, strong broad C-O-C absorption at $1160-1050 \mathrm{~cm}^{-1}$, No $\mathrm{COOH}$ absorption at 1750 $\mathrm{cm}^{-1}$. Hydroxyl-Value 174 (according to DIN 53240). Molecular weight was 321 (calculated from the Hydroxyl-Value).

A mixture was made of approximately $60 \% 1$ dodecanol (compound 1, with $\mathrm{R}=\mathrm{C}_{12} \mathrm{H}_{25}$ and $\mathrm{n}=$ 4) and approximately $40 \%$ 1-tetradecanol (1, with $R$ $=\mathrm{C}_{14} \mathrm{H}_{29}$ and $\mathrm{n}=4$ ) ethoxylated with $5 \mathrm{EO}$ (Union Carbide). The following analytical data were determined for the IR-spectrum: Strong broad $\mathrm{OH}$ absorption at $3470 \mathrm{~cm}^{-1}$, strong broad $\mathrm{C}-\mathrm{H}$ absorption at $2960-2840 \mathrm{~cm}^{-1}$, strong broad C-O-C absorption at $1160-1050 \mathrm{~cm}^{-1}$, No COOH absorption at $1750 \mathrm{~cm}^{-1}$. Hydroxyl-Value 140 (according to DIN 53240). Molecular weight was 400 (calculated from the Hydroxyl-Value).

\section{Ethoxylated sec-alcohols}

A mixture of random hydroxylated secondary tetradecanols (compound 1, with $\mathrm{R}=$ iso- $\mathrm{C}_{14} \mathrm{H}_{29}$ and $n=2$ ) and sec pentadecanols (compound $\mathbf{1}$, with $\mathrm{R}=$ iso- $\mathrm{C}_{15} \mathrm{H}_{31}$ and $\mathrm{n}=2$ ) ethoxylated with 3 $\mathrm{EO}$, where the ethoxyl group attached randomly to all secondary hydroxyl groups (Union Carbide) was used. The following analytical data were determined for the IR-spectrum: Strong broad $\mathrm{OH}$ absorption at $3470 \mathrm{~cm}^{-1}$, strong broad C-H absorption at $2960-$ $2840 \mathrm{~cm}^{-1}$, strong broad C-O-C absorption at $1160-1050 \mathrm{~cm}^{-1}$, no $\mathrm{COOH}$ absorption at 1750 $\mathrm{cm}^{-1}$. Hydroxyl-Value 159 (according to DIN 53240). Molecular weight was 352 (calculated from the Hydroxyl-Value).

\section{Ethoxylated alkylphenols}

Nonylphenol ethoxylated with 10 EO (compound 7, with $\mathrm{R}=\mathrm{C}_{9} \mathrm{H}_{19}$ and $\mathrm{n}=9$ ) (Degussa-Hüls) was applied. The following analytical data were determined for the IR-spectrum: Strong broad $\mathrm{OH}$ absorption at $3470 \mathrm{~cm}^{-1}$, strong broad $\mathrm{C}-\mathrm{H}$ absorption at $2960-2840 \mathrm{~cm}^{-1}$, strong broad C-O-C absorption at $1160-1050 \mathrm{~cm}^{-1}$, no COOH absorption at $1750 \mathrm{~cm}^{-1}$. Hydroxyl-Value 85 (according to DIN 53240). Molecular weight 659 (calculated from the Hydroxyl-Value).

Nonylphenol ethoxylated was mixed with 12 EO (compound 7, with $\mathrm{R}=\mathrm{C}_{9} \mathrm{H}_{19}$ and $\mathrm{n}=11$ ) (Degussa-Hüls). The following analytical data were determined for the IR-spectrum: Strong broad $\mathrm{OH}$ absorption at $3470 \mathrm{~cm}^{-1}$, strong broad $\mathrm{C}-\mathrm{H}$ absorption at $2960-2840 \mathrm{~cm}^{-1}$, strong broad C-O-C absorption at $1160-1050 \mathrm{~cm}^{-1}$, no $\mathrm{COOH}$ absorption at $1750 \mathrm{~cm}^{-1}$. Hydroxyl-Value 78 (according to DIN 53240). Molecular weight 718 (calculated from the Hydroxyl-Value). 


\subsection{Oxidation of ethoxylated n-primary alcohols with Platinum}

\section{Oxidation of ethoxylated n-primary alcohol} with 3 EO units

A 500-ml round bottom flask fitted with thermometer, gas inlet tube, mechanical stirrer, reflux condenser and heating jacket with temperature control was employed. The charge consisted of $1,16 \mathrm{~g}$ Platindioxid $\left(\mathrm{PtO}_{2}\right), 20 \mathrm{~g}$ ethoxylated n-primary alcohol with $3 \mathrm{EO}$ units (as described under 2.1), 4,8 g NaHCO3 (Merck) and $210 \mathrm{ml}$ water.

The procedure described in brief entails $170 \mathrm{ml}$ of water and $1.16 \mathrm{~g} \mathrm{PtO}_{2}$ put in the reaction flask where nitrogen was bubbled through the stirred suspension to expel any oxygen. Hydrogen in a ratio of $80 \mathrm{ml} / \mathrm{min}$ was then passed through the suspension for $30 \mathrm{~min}$ at room temperature to activate the catalyst. After interruption of the hydrogen flow, nitrogen was flushed again to remove any residual amount of hydrogen or oxygen, as this could be explosive. $4,8 \mathrm{~g}$ of sodium hydrogen carbonate dissolved in $40 \mathrm{ml}$ of water were then added and the suspension was heated up to $80^{\circ} \mathrm{C}$. At this temperature, $20 \mathrm{~g}$ ethoxylated $\mathrm{n}$ primary alcohol with 3 EO units was added. Oxygen was then supplied to the mixture at a rate of 135 $\mathrm{ml} / \mathrm{min}$. The reaction mixture was vigorously stirred for $2 \mathrm{~h}$ at $68-70{ }^{\circ} \mathrm{C}$, while the oxygen uptake was measured with a gas burette. After completion of the reaction, the mixture was filtered, the filtrate was acidified to $\mathrm{pH}-1$ with concentrated hydrochloric acid and the solvent was extracted with chloroform. The combined extracts were washed with a saturated (at $20^{\circ} \mathrm{C}$ ) sodium sulfate solution until the absence of chloride $\left(\mathrm{AgNO}_{3}\right.$ test), dried with anhydrous sodium sulfate and the solvent was evaporated to dryness under vacuum. The product was obtained as a colorless liquid.

\section{Oxidation of ethoxylated n-primary alcohol with $5 \mathrm{EO}$ units}

The oxidation was carried out in the experimental configuration described under "Oxidation of ethoxylated n-primary alcohol with 3 EO units" section. The charge consisted of $10 \mathrm{~g}$ Palladium, $10 \%$ on charcoal $(1 \mathrm{~g} \mathrm{Pd}), 30 \mathrm{~g}$ ethoxylated $n$ - primary alcohol with 5 EO units, 210 $\mathrm{ml}$ water and $2.3 \mathrm{~g} \mathrm{NaOH}$ (Merck).

The procedure described in brief entails $160 \mathrm{ml}$ of water and $10 \mathrm{~g} \mathrm{Pd}$-catalyst put in the reaction flask where hydrogen was bubbled through the stirred suspension with a flow rate of $80 \mathrm{ml} / \mathrm{min}$ for $25 \mathrm{~min}$ at room temperature. Sodium hydroxide dissolved in $50 \mathrm{ml}$ of water was added, then the hydrogen flow was released for an additional 5 min and the suspension was heated up to $80^{\circ} \mathrm{C}$. At this temperature, $30 \mathrm{~g}$ ethoxylated $\mathrm{n}$-primary alcohol with 5 EO was added. Nitrogen was used for the removal of hydrogen. Finally, oxygen was carried through the vigorously stirred reaction mixture at a flow rate of $135 \mathrm{ml} / \mathrm{min}$. The temperature was between $79-84^{\circ} \mathrm{C}$, the reaction time $150 \mathrm{~min}$, while oxygen uptake was measured with a gas burette. The catalyst was filtered off; the filtrate was acidified with concentrated $\mathrm{HCl}$ and extracted with chloroform. The extraction procedure was repeated twice. At the end, the extract was washed with sodium sulfate (10\% aqueous solution) to remove any inorganic acid and filtered. The acid was obtained as a colourless liquid after evaporation of the solvent under vacuum.

\subsection{Oxidation of ethoxylated sec alcohols with Palladium}

The oxidation was carried out in the experimental configuration described under the "Oxidation of ethoxylated n-primary alcohol with 3 EO units" section. The charge consisted of $10 \mathrm{~g}$ Palladium, $10 \%$ on charcoal ( $1 \mathrm{~g} \mathrm{Pd}), 22 \mathrm{~g}$ randomly hydroxylated sec. tetradecanols and pentadecanols ethoxylated with $3 \mathrm{EO}$ units, $3.5 \mathrm{~g} \mathrm{KOH}$ (Merck) and $420 \mathrm{ml}$ water. The oxidation and the isolation of the product were carried out as described under the "Oxidation of ethoxylated n- primary alcohol with 5 EO units" section. However, the catalyst was suspended in $340 \mathrm{ml}$ water and the nonionic diluted in $80 \mathrm{ml}$ water. The reaction temperature was between $85-89{ }^{\circ} \mathrm{C}$ and the reaction time was 90 $\mathrm{min}$. The obtained product was a pale yellow liquid.

\subsection{Oxidation of ethoxylated nonylphenol with Palladium}

\section{Oxidation of ethoxylated nonylphenol with 10 EO units}

The oxidation was carried out in the experimental configuration described under the "Oxidation of ethoxylated n-primary alcohol with 3 EO units" section. The charge consisted of $10 \mathrm{~g}$ Palladium, $10 \%$ on charcoal (1g Pd), $30 \mathrm{~g}$ ethoxylated nonylphenol with $10 \mathrm{EO}$ units, $210 \mathrm{ml}$ water and $2.3 \mathrm{~g} \mathrm{NaOH}$ (Merck). The oxidation and the isolation of the product were carried out as described under the "Oxidation of ethoxylated nprimary alcohol with $5 \mathrm{EO}$ units" section. However, the reaction temperature was between $80-83{ }^{\circ} \mathrm{C}$ and the reaction time $90 \mathrm{~min}$. The obtained product was a pale yellow liquid.

\section{Oxidation of ethoxylated nonylphenol with 12 EO units}

The oxidation was carried out in the experimental configuration described under the "Oxidation of ethoxylated n-primary alcohol with 3 EO units" section. The charge consisted of $10 \mathrm{~g}$ Palladium, $10 \%$ on charcoal (1g Pd), $30 \mathrm{~g}$ ethoxylated nonylphenol with $12 \mathrm{EO}$ units, $120 \mathrm{ml}$ water and $2.2 \mathrm{~g} \mathrm{NaOH}$ ((Merck). The oxidation and 
the isolation of the product were carried out as described under the "Oxidation of ethoxylated nprimary alcohol with 5 EO units" section. However, the reaction temperature was between $80-83{ }^{\circ} \mathrm{C}$. The obtained product was a pale yellow liquid.

\subsection{Yield determination of the ethoxy carboxylic acids using an ion-exchange column}

A Dowex $21 \mathrm{~K}$ column was used to perform the ion-exchange analysis. The resin contained in the column exceeded four times the theoretical amount (calculated from the Acid Value). The resin was initially washed with $\mathrm{NaOH}(2 \mathrm{~N})$ until all chloride was removed $\left(\mathrm{AgNO}_{3}\right.$ test), then with water until the $\mathrm{pH}$ turned to neutral and finally with methanol until all water was removed.

A sample containing 3-5 $\mathrm{g}$ of each reaction product (obtained from the ethoxylated alcohols) was applied to the column and then eluted with methanol. By applying methanol the neutral material of the sample was eluted from the column and obtained at a later time with evaporation.

A second elution was performed with a mixture containing $\mathrm{CH}_{3} \mathrm{OH}$ and concentrated $\mathrm{HCl}(9: 1 \mathrm{v} / \mathrm{v})$ until the whole column length changed its colour to light yellow. This second eluate was left for a minimum of 2 hours at room temperature to complete the esterification of the eluted acids. The majority of the methanol contained in the second eluate was then separated from the mixture by applying evaporation under vacuum at $20^{\circ} \mathrm{C}$. The concentrate was taken up in water and the resultant solution was extracted with chloroform. The chloroform-phase was washed with aqueous sodium sulfate until the absence of any residual chloride, and dried over sodium sulfate. After evaporation of the solvent, the methyl ester of the ethoxy carboxylic acids were obtained and weighed. From their weight the initial amount of free acids was calculated.

\subsection{Further experiments with Platinum, Palladium, Rhodium and Ruthenium}

Further experiments on the oxidization of ethoxylated alcohols to corresponding acids with Platinum catalyst were carried out as described under the "Oxidation of ethoxylated n-primary alcohol with 3 EO units" section and with Palladium, Rhodium and Ruthenium catalysts as described under the "Oxidation of ethoxylated n- primary alcohol with 5 EO units" section. The reaction conditions are presented in table 1.

\section{RESULTS}

\subsection{Analytical data of the reaction products}

The reaction products described in sections 2.22.4 are presented in table 2. According to these the yields, the reaction products varied between 19.6 and $28.6 \%$. All of the products showed a strong absorption at 1750 and $1120 \mathrm{~cm}^{-1}$ which is

Table 1

Oxidation of ethoxylated n-primary alcohols and secondary alcohols with noble catalysts

\begin{tabular}{|c|c|c|c|c|c|c|c|c|}
\hline \multirow{2}{*}{$\begin{array}{l}\text { Experiment } \\
\text { Number }\end{array}$} & \multirow{2}{*}{$\begin{array}{c}\text { Noble Metal } \\
\text { Catalyst }\end{array}$} & \multicolumn{3}{|c|}{ Charge Ratios } & \multirow{2}{*}{$\begin{array}{c}\text { Base } \\
\text { (mole/ mole } \\
\text { non-ionic) }\end{array}$} & \multirow{2}{*}{$\begin{array}{c}\text { Temperature } \\
\left({ }^{\circ} \mathrm{C}\right)\end{array}$} & \multirow[b]{2}{*}{ Time (min) } & \multirow[b]{2}{*}{ Nonionic } \\
\hline & & Catalyst & Nonionic & Water & & & & \\
\hline 1 & $\mathrm{Pt}$ & 1 & 30 & 210 & $\mathrm{NaOH}$ & $79-83$ & 150 & n-alc.3EO ${ }^{1}$ \\
\hline 2 & $\mathrm{Pt}$ & 1 & 30 & 210 & $\mathrm{NaOH}$ & $79-83$ & 150 & n-alc.3EO \\
\hline 3 & $\mathrm{Pt}$ & 1 & 20 & 210 & $\mathrm{NaHCO}_{3}$ & $68-70$ & 120 & n-alc.3EO \\
\hline 4 & $\mathrm{Pd}$ & 1 & 20 & 300 & $\mathrm{NaHCO}_{3}$ & $78-82$ & 120 & n-alc.3EO \\
\hline 5 & $\mathrm{Pd}$ & 1 & 30 & 210 & $\mathrm{NaHCO}_{3}$ & $78-82$ & 120 & n-alc.3EO \\
\hline 6 & $\mathrm{Pd}$ & 1 & 30 & 210 & $\mathrm{NaOH}$ & $79-84$ & 150 & n-alc.3EO \\
\hline 7 & $\mathrm{Pd}$ & 1 & 20 & 300 & $\mathrm{NaHCO}_{3}$ & $75-78$ & 120 & n-alc.3EO \\
\hline 8 & $\mathrm{Pd}$ & 1 & 20 & 140 & $\mathrm{NaHCO}_{3}$ & $72-77$ & 300 & n-alc.3EO \\
\hline 9 & $\mathrm{Ru}$ & 1 & 20 & 210 & $\mathrm{NaOH}$ & $84-91$ & 210 & n-alc.3EO \\
\hline 10 & $\mathrm{Ru}$ & 1 & 15 & 210 & $\mathrm{NaOH}$ & $84-93$ & 180 & n-alc.3EO \\
\hline 11 & $\mathrm{Rh}$ & 1 & 30 & 300 & $\mathrm{NaOH}$ & $84-91$ & 150 & n-alc.3EO \\
\hline 12 & $\mathrm{Rh}$ & 1 & 30 & 210 & $\mathrm{NaOH}$ & $85-90$ & 90 & n-alc.3EO \\
\hline 13 & $\mathrm{Pd}$ & 1 & 28 & 210 & $\mathrm{NaOH}$ & $80-85$ & 150 & n-alc.5EO ${ }^{2}$ \\
\hline 14 & $\mathrm{Pd}$ & 1 & 30 & 210 & $\mathrm{NaOH}$ & $80-85$ & 150 & n-alc.5EO \\
\hline 15 & $\mathrm{Pd}$ & 1 & 15 & 210 & $\mathrm{NaOH}$ & $85-90$ & 135 & n-alc.5EO \\
\hline 16 & $\mathrm{Pd}$ & 1 & 30 & 210 & $\mathrm{NaOH}$ & $78-82$ & 80 & sec-alc.3EO ${ }^{3}$ \\
\hline 17 & $\mathrm{Pd}$ & 1 & 22 & 420 & $\mathrm{KOH}$ & $85-89$ & 150 & sec-alc.3EO \\
\hline 18 & $\mathrm{Pd}$ & 1 & 30 & 210 & $\mathrm{NaOH}$ & $80-83$ & 150 & Alkylphenol 10EO \\
\hline 19 & $\mathrm{Pd}$ & 1 & 30 & 120 & $\mathrm{NaOH}$ & $80-82$ & 150 & Alkylphenol 12EO \\
\hline
\end{tabular}

1) n-alc.3EO = mixture of approximately $60 \%$ 1-dodecanol and approximately $40 \% 1$-tetradecanol ethoxylated with 3 EO units

2) $\mathrm{n}$-alc. $5 \mathrm{EO}=$ mixture of approximately $60 \% 1$-dodecanol and approximately $40 \% 1$-tetradecanol ethoxylated with 5 EO units.

3) sec.-alc. $3 E O=$ mixture of random hydroxylated secondary tetradecanols and secondary pentadecanols ethoxylated with 3 EO units.

4) alkylphenol $10 \mathrm{EO}=$ ethoxylated Nonylphenol with $10 \mathrm{EO}$ units.

5) alkylphenol $12 \mathrm{EO}=$ ethoxylated Nonylphenol with $12 \mathrm{EO}$ units 
Table 2

Analytical Data of the Reaction Products

\begin{tabular}{|c|c|c|c|c|c|c|c|c|c|}
\hline \multirow[b]{3}{*}{ Alcohol } & \multirow[b]{2}{*}{ Catalyst } & \multirow[b]{2}{*}{ Yield } & \multicolumn{3}{|c|}{ IR - spectrum absorption } & & & & \multirow[b]{2}{*}{ Acid Value } \\
\hline & & & $\mathrm{COOH}$ & C-O-C & $\mathrm{OH}$ & \multicolumn{3}{|c|}{ Aromatic Band } & \\
\hline & & & $1750 \mathrm{~cm}^{-1}$ & $1120 \mathrm{~cm}^{-1}$ & $3500 \mathrm{~cm}^{-1}$ & $750 \mathrm{~cm}^{-1}$ & $1510 \mathrm{~cm}^{-1}$ & $1610 \mathrm{~cm}^{-1}$ & \\
\hline n- primary 3 E.O. & $\mathrm{Pt}$ & $19,6 \mathrm{~g}$ & Strong & Strong & Absent & Absent & Absent & Absent & 164,0 \\
\hline n- primary 5 E.O. & $\mathrm{Pd}$ & $28,1 \mathrm{~g}$ & Strong & Strong & Absent & Absent & Absent & Absent & 124,2 \\
\hline sec 3 E.O. & $\mathrm{Pd}$ & $28,6 \mathrm{~g}$ & Strong & Strong & Absent & Absent & Absent & Absent & 141,3 \\
\hline Nonylphenol 10 E.O. & $\mathrm{Pd}$ & 27,0 & Strong & Strong & Absent & Medium & Medium & Medium & 74,2 \\
\hline Nonylphenol 12 E.O. & $\mathrm{Pd}$ & 26,0 & Strong & Strong & Absent & Medium & Medium & Medium & 67,8 \\
\hline
\end{tabular}

characteristic of the carboxyl group and the C-O-C bound respectively. On the other hand, no absorption was present at $3500 \mathrm{~cm}^{-1}$ which indicates the absence of the hydroxyl group. From these data the conversion of the majority of the initial amount of alcohol could be concluded. Also both products prepared from nonylphenol showed characteristics of aromatic compound absorptions at 750,1510 and $1610 \mathrm{~cm}^{-1}$.

\subsection{Purities and yields of the reaction products}

The acid value of the oxidation products was determined at the end of the reaction according to the DGF-method C-V 2 (81). The measured acid value compared with the theoretical value was used for the calculation of product purity. In addition, the yield of the products was determined with the ion exchange column. In this way, the degradation of the ethoxy-chain can be calculated from the comparison of the purity (derived from the acid value) and the yield (derived from the ion-exchange column). The results are presented in Table 3.

\section{DISCUSSION}

The results show that all three types of ethoxylated alcohols used in the current study (nprimary fatty alcohols, random hydroxylated sec alcohols and alkylphenols) can be oxidised with oxygen using noble metal catalysts. All the catalysts used in alkaline aqueous solutions are suitable for the oxidation of the ethoxylated alcohols to the corresponding acids with virtually no degradation of the ethoxyl chain.

The obtained products are colourless to paleyellow liquids. The ethoxy carboxylic acids produced from the ethoxylated n-primary alcohol with 3 EO

Table3

Purity of the reaction products calculated from the acid value and yields calculated from the ion exchange column

\begin{tabular}{ccccl}
\hline $\begin{array}{c}\text { Experiment } \\
\text { Number }\end{array}$ & Nonionic & Purity & Yield & Remarks \\
\hline 1 & n-alc.3EO & 90 & 89 & \\
2 & n-alc.3EO & 92 & 90 & \\
3 & n-alc.3EO & 99 & - & See 2.2.1 \\
4 & n-alc.3EO & 93 & 92 & \\
5 & n-alc.3EO & 93 & - & \\
6 & n-alc.3EO & 96 & - & Catalyst used for second time without any special treatment \\
7 & n-alc.3EO & 75 & - & Catalyst used for second time without any special treatment \\
8 & n-alc.3EO & 76 & - & \\
9 & n-alc.3EO & 63 & 59 & \\
10 & n-alc.3EO & 55 & 52 & \\
11 & n-alc.3EO & 80 & 75 & \\
12 & n-alc.3EO & 74 & 67 & \\
13 & n-alc.5EO & 90 & 89 & \\
14 & n-alc.5EO & 92 & 90 & See 2.2.2 \\
15 & n-alc.5EO & 97 & - & \\
16 & sec-alc.3EO & 85 & 83 & \\
17 & sec-alc.3EO & 93 & 91 & See 2.3 \\
18 & Alkylphenol 10EO & 89,5 & 88 & See 2.4.1 \\
19 & Alkylphenol 12EO & 89 & 87 & See 2.4.2 \\
\hline
\end{tabular}

1) n-alc.3EO = mixture of approximately $60 \%$ 1-dodecanol and approximately $40 \%$ 1-tetradecanol ethoxylated with 3 EO units.

2) $\mathrm{n}$-alc.5EO = mixture of approximately $60 \% 1$-dodecanol and approximately $40 \% 1$-tetradecanol ethoxylated with 5 EO units.

3) sec.-alc. $3 E O=$ mixture of random hydroxylated secondary tetradecanols and secondary pentadecanols ethoxylated with 3 EO units.

4) alkylphenol $10 \mathrm{EO}=$ ethoxylated Nonylphenol with $10 \mathrm{EO}$ units.

5) alkylphenol $12 \mathrm{EO}=$ ethoxylated Nonylphenol with $12 \mathrm{EO}$ units 
units and the randomly hydroxylated sec alcohols with 3 EO units are hardly soluble in water. The ethoxy carboxylic acids derived from the n-primary alcohol with $5 \mathrm{EO}$ units as well as the ethoxylated alkylphenols with 10 or $12 \mathrm{EO}$ units dissolve well in water.

The ethoxylated aliphatic alcohols and alkylphenols were converted to carboxylic acids in high yields (exceeding 90\%) when Palladium and Platinum catalysts were used. The other two catalysts show poorer conversion amounts. In fact, yields of about $80 \%$ were achieved using Rhodium and of about $60 \%$ using Ruthenium.

According to the results, it can be concluded that the catalytic effect of Platinum was comparable to that of Palladium. Both catalysts are highly efficient for the catalysis of the dehydrogenation/oxidation process of the ethoxylated alcohols in the alkaline solution without significant degradation of the ethoxyl chain. Rhodium and Ruthenium gave significantly lower yields and a degradation of the ethoxyl group could be assumed.

The extension of a possible degradation was determined by applying an ion-exchange column. This method provides an independent test for the purity of the obtained products based on the gravimetrical determination of the methylated ethoxy carboxylic acids. The comparison of the purities calculated from the acid value and the yields determined by the ion-exchange column give the amount of the degradation of the ethoxyl chain. From the results, a marginal degradation of about $1-2 \%$ by using Pt or Pd and a higher degradation of about 6$9 \%$ by using Rh or Ru catalysts were determined.

The temperature and the concentration of the ethoxylated alcohols in water are important factors for the conversion to ethoxy carboxylic acids. The reaction proceeds satisfactorily at $80-90{ }^{\circ} \mathrm{C}$ with concentrations of ethoxylated primary and sec alcohols in water under 14\%. At higher concentrations the reaction begins with a fast oxygen uptake but the reaction mixture becomes rapidly semi-solid. This leads to a low conversion probably due to the poor contact of the substrate, the catalyst and oxygen. The reactions of the ethoxylated alkylphenols with 10 and 12 EO units also result in satisfactory conversions at higher concentrations of about $25 \%$ because of the better solubility of the product in the alkaline solution.

The presence of a base is also important. In aqueous alkaline solutions the Pd-catalysed oxidation of the n-primary alcohol with $3 \mathrm{EO}$ units is almost complete in 2-4 hours. The same reaction without the use of a base proceeded significantly slower and gave a conversion smaller than $70 \%$ after 7 hours. At higher concentrations of nonionic in water, $\mathrm{NaOH}$ or $\mathrm{KOH}$ are more suitable than $\mathrm{NaHCO}_{3}$.

Another important reaction factor is the weight ratio of catalyst to nonionic. A ratio of catalyst consisting of non ionic of 1:15 in most cases results in higher conversion yields than a ratio of $1: 30$. However, in some cases (reactions 1, 2, 6, 7, 11 and 13 presented in Table 1) an increase in this ratio has no effect on the conversion ratio. In every case, due to the high cost of the catalyst compared with the limited improvement of the conversion, an increase in the catalyst to non ionic ratio is not applicable.

The use of Palladium is encouraged for further investigations as this catalyst is less expensive than Platinum. Also, further investigations with multiple uses of Palladium are recommended since, as in initial trials in this work (experiments 7, 8 described in Table 1), the reuse of the catalyst had some success but further studies are required to define the life-time and losses in the catalyst.

\section{CONCLUSIONS}

Ethoxylated n-primary and secondary aliphatic alcohols, as well as ethoxylated alkylphenols, can be converted to the corresponding carboxylic acids in yields over $90 \%$ by oxidation with oxygen in the presence of a base $\left(\mathrm{NaOH}, \mathrm{KOH}, \mathrm{NaHCO}_{3}\right)$ using palladium and platinum without significant degradation of the ethoxyl chain. Rhodium and ruthenium are less efficient as catalysts and gave, in comparison, lower yields of about $80 \%(\mathrm{Rh})$ and $60 \%(\mathrm{Ru})$ and some ethoxyl chain degradation.

\section{REFERENCES}

Aalbers JG. 1964. Lauryl (poly-1-oxapropene) oxaethane carboxylic acids, Drukkerij Wed. G.Van Soenst N. V., Amsterdam.

Gangwal VR, van der Schaaf J, Kuster BFM, Schouten JC. 2005. Influence of $\mathrm{pH}$ on noble metal catalysed alcohol oxidation: reaction kinetics and modeling. J. Catal. 229, 389-403.

Haines AH. 1988. Methods for the Oxidation of Organic Compounds: Alcohols, Alcohol Derivatives, Alkyl Halides, Nitroalkanes, Alkyl Azides, Carbonyl Compounds, Hydroxyarenes, and Aminoarenes, Academic Press, London.

Heyns K, Paulsen H. 1957. Neuere Methoden der präparativen organischen Chemie II. 8. Selektive katalytische Oxydationen mit EdelmetallKatalysatoren. Angew. Chem. 69, 600-608.

Heyns K, Blazejewicz L. 1960. Katalytische oxydation von primären und sekundären hydroxylverbindungen mit sauerstoff am platinkontakt in flüssiger phase: Über katalytische oxydationen-XIV, Tetrahedron 9, 67-75.

Heyns K, Paulsen H. 1962. Selective catalytic oxidation of carbohydrates, employing plantinum catalysts. Adv. Carbohydr. Chem. 17, 169-221.

Korovchenko P, Donze C, Gallezot P, Besson M. 2007. Oxidation of primary alcohols with air on carbonsupported platinum catalysts for the synthesis of aldehydes or acids, Catal. Today 121, 13-21.

Mallat T, Baiker A. 2004. Oxidation of Alcohols with Molecular Oxygen on Solid Catalysts. Chem. Rev. 104, 3037-3058.

Mallat T, Baiker A. 1995. Catalyst potential: a key for controlling alcohol oxidation in multiphase reactors. Catal. Today 24, 143-150.

Mallat T, Baiker A. 1994. Oxidation of alcohols with molecular oxygen on platinum metal catalysts in aqueous solutions. Catal. Today 19, 247-284. 
Röper H. 1990. in: F.W. Lichtenthaler (Ed.) Carbohydrates as Organic Raw Materials, VCH, Weinheim, pp. 267-288.

Schiller G. 1990. in: Houben, Weyl, Müller (Eds.), Methoden der Organischen Chemie, 4th edition, Georg Thieme Verlag, Stuttgart, p.339.

Sheldon RA, Arends IWCE, Dijksman A. 2000. New developments in catalytic alcohol oxidations for fine chemicals synthesis. Catal. Today 57, 157-166.

van Bekkum H. 1990. in: F.W. Lichtenthaler (Ed.) Carbohydrates as Organic Raw Materials, $\mathrm{VCH}$, Weinheim, pp. 289-310.
Vinke P, de Wit D, de Goede ATJW, van Bekkum H. 1992. in: Ruiz P., Delmon B. (Eds.) Studies in Surface Science and Catalysis, Vol. 72: New Developments in Selective Oxidation by Heterogeneous Catalysis, Elsevier Amsterdam, pp.1-20.

Zhan BZ, Thompson A. 2004. Recent developments in the aerobic oxidation of alcohols. Tetrahedron 60, 2917-2935.

Recibido: 7/1/09 Aceptado: 6/2/09 